\title{
Occurence of Echinococcus multilocularis in red foxes (Vulpes vulpes) in southern Poland
}

\author{
A. BORECKA, J. GAWOR, M. MALCZEWSKA, A. MALCZEWSKI \\ Institute of Parasitology of the Polish Academy of Sciences, Twarda 51/55, 00-818 Warsaw, Poland, \\ E-mail: ab@twarda.pan.pl
}

\begin{abstract}
Summary
The prevalence of Echinococcus multilocularis in 214 red foxes (Vulpes vulpes) in the southern part of Poland (Małopolskie voivodship) was evaluated post mortem in 2005. Infected foxes were found in 8 districts within 17 examined, with the prevalence from $10.0 \%$ to $63.9 \%$ (a mean $20.1 \%$ in the whole study area). The highest prevalence $(41.2 \%$ and $63.9 \%)$ was revealed in two districts, in the south and the east of the province, respectively. The high prevalence of E. multilocularis in red foxes in the region previously recognised as that of low parasite endemicity provides evidence for the need of regular screening of the current epidemiological situation in foxes as well as the monitoring of humans from risk groups for early recognition of possible $\mathrm{AE}$ cases.
\end{abstract}

Keywords: Echinococcus multilocularis; red fox; prevalence; Poland

\section{Introduction}

Echinococcus multilocularis, occurring throughout the northern hemisphere, exploits predator-prey systems between carnivores and their prey species for transmission. The principal definitive hosts are canids, e.g. foxes (Vulpes spp., Alopex lagopus) and coyotes (Canis latrans) consuming rodents as prey (Eckert et al., 2001). In Poland, racoon dogs (Nyctereutes procyonoides) have also been established as final hosts (Machnicka et al., 2002, Gawor \& Malczewski, 2005). The metacestodes of E. multilocularis are adapted to small rodents, particularly from the family Arvicolidae (common vole - Microtus arvalis, water vole Arvicola terrestris, musk rat - Ondatra zibethicus) as their intermediate hosts. Humans, domestic and wild pigs, horses, dogs and monkeys have been described as aberrant, usually accidental hosts of the metacestode stage of $E$. multilocularis (Eckert et al., 2001). The larval stage of this tapeworm generates human alveolar echinococcosis (AE). Humans acquire E. multilocularis infection via the oral route, and it is assumed that egg transmission may occur through contaminated hands (after contact with infected definitive hosts, soil or plants) or by ingestion of food contaminated with eggs (Deplazes \& Eckert, 2001). Some reports suggest that egg transmission may also occur by waterborne routes (Eckert et al., 2001). The cancer-like proliferation of the E. multilocularis in the human host may lead to a severe disease which is often fatal if not diagnosed in the early stages and correctly treated. Lethality rates were approximately $100 \%$ in certain groups of untreated patients before the 1970s, when modern methods of treatment were not yet established.

The aim of the study was to determine the occurrence of $E$. multilocularis in red foxes in the southern part of Poland (Małopolskie voivodship), an area recorded as of very low prevalence of the parasite in the previous study. This region borders the highly endemic areas, i.e. Podkarpackie voivodship (south-east of Poland) (EchinoRisk 2005) and north-east Slovak Republic (Dubinsky et al., 2006).

\section{Materials and methods}

In 2005, 214 red foxes (87 females, 127 males) were collected during hunting in 17 districts among 22 belonging to the Małopolskie voivodship. The samples were individually labelled with an identification number and information about locality, age and gender. Before necropsy the carcasses were deep frozen at $-80{ }^{\circ} \mathrm{C}$ up to 7 days to exclude the risk of infection (Veit et al., 1995). The intestinal scraping technique (IST) was used to detect $E$. multilocularis specimens (Deplazes \& Eckert, 1996). The small intestine was divided into five parts and opened in full length. A microscopic slide was used to make mucosal scrapings, three from each of the five parts of the small 
intestine (a total of 15 scrapings). Scrapings from each part were transferred to a plastic Petri dish $(90 \times 90 \mathrm{~mm})$ and mixed with distilled water. The material was then examined under 20x magnification. The parasites were differentiated according to Vogel (1957).

\section{Results and discussion}

In Małopolskie voivodship, among the 214 red foxes (Vulpes vulpes) examined, 43 were found infected (a mean prevalence of $20.1 \%$, confidence interval $14.72<\mathrm{p}<25.46$ ). From 1 to 23 animals were found infected in 8 districts, while in 9 districts among 66 foxes (from 1 to 25 in each locality) no infected were found (Fig. 1).

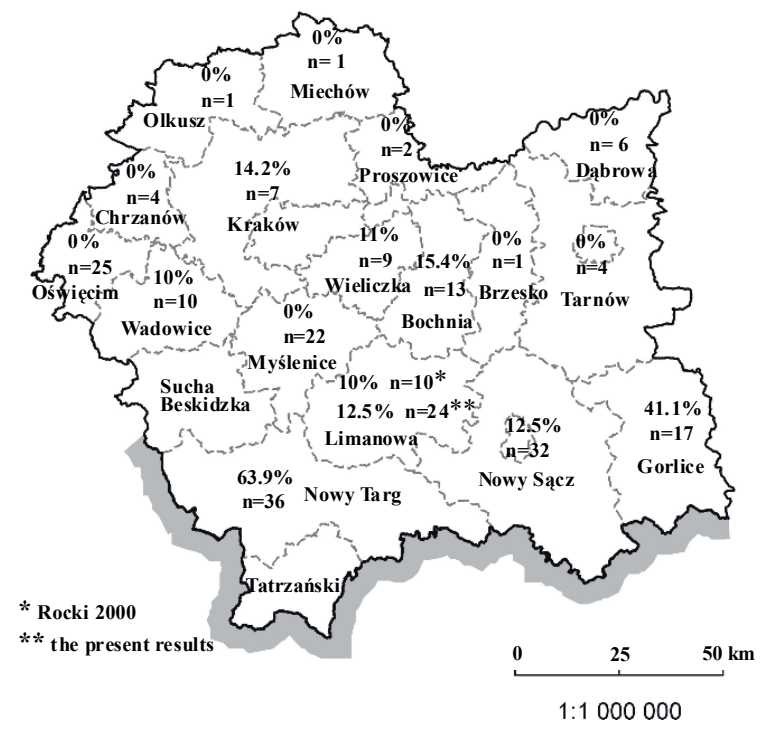

Fig. 1. The prevalence of Echinococcus multilocularis in 214 red foxes in Małopolskie voivodship (2000-2005)

A previous study in this region in 1997 - 1998 revealed 0.6 $\%$ infected among the 157 examined (Rocki, 2000), but detailed data on the foxes' origin are unknown except in the Limanowa district, where among 10 examined one infected was found. Nevertheless, the high prevalence (a mean of $36.8 \%$ ) found in the east-neighbouring region (Carpathian Foothill province) in 2003 - 2004 (EchinoRisk, 2005) as well as the human case diagnosed in the southern part of Małopolskie voivodship (district Nowy Targ) suggested the need to screen the current epidemiological situation of E. multilocularis in foxes in this area. This administrative region has an area of $15100 \mathrm{~km}^{2}$, equal to $4.8 \%$ of the area of Poland. The landscape is uplandmountainous with elevation between 600 and $1315 \mathrm{~m}$ above sea level, consists of forests $(28.4 \%)$ and agricultural areas. Also six National Parks and several Nature Reserves are situated there $(12.1 \%)$. In Nowy Targ and Gorlice districts recognised as highly endemic regions forests cover $37 \%$ and $43.4 \%$ of the area, respectively. Farmland areas, wood edges and woodlots are virtually exclusive habitats where fox dens are situated. In an area with $21 \%$ forest coverage, only $2 \%$ of all dens were located in open habi- tats (Goszczyński, 1985).

The tapeworm is likely to occur in colder climates and its distribution range is limited by temperatures and rainfall and this also applies at the regional level (Dubinsky et al., 2006). Veit et al. (1995) examined the sensitivity of $E$. multilocularis eggs to environmental conditions. Their results showed that the eggs are resistant in the outer environment in the endemic areas of the south-western Germany. Survival of E. multilocularis oncospheres of more than 100 days was observed during various seasons of the year (March - August, December - May) with the maximum endurance up to 240 days. Similar climatic conditions favouring the potential of intermediate hosts to be infected are in Małopolskie voivodship, with a mean annual temperature $6{ }^{0} \mathrm{C}-8.4{ }^{0} \mathrm{C}\left(\max .37{ }^{\circ} \mathrm{C}\right.$, min. $\left.-38{ }^{\circ} \mathrm{C}\right)$ and rainfall $740-995 \mathrm{~mm}$ in the years $1996-2006$ (Concise Statistical Yearbook of Poland, 2007). Reiterova et al. (2006) and Miterpakova et al. (2006) found high E. multilocularis prevalence in the northern part of Slovakia $(36.7 \%-57.9 \%)$ bordering with the examined areas in Poland. Transborder migration of foxes between Poland and the Slovak Republic is probable along the whole border except the south of Nowy Targ district where the High Tatra Mountains make the natural barrier. The high prevalence of E. multilocularis was found in the border zone at the east Carpathian region, with a mean $45.7 \%$ foxes infected in the Polish borderland and $35.0 \%$ in the Slovak border (Dubinsky et al., 2006).

The recent study in Gorlice and Limanowa districts (Małopolskie voivodship) has shown no foxes infected, probably due to the low number of the examined (7 and 3 animals, respectively) (Reiterova et al., 2006). In the present examinations 17 and 24 foxes were necropsied, with 7 and 3 infected in both districts, respectively.

The first record of E. multilocularis in foxes in Poland was revealed in 1994 in the northern part of the country (Malczewski et al., 1995). Studies within the period $1994-2000$ when a total of 3573 foxes were sampled from $90 \%$ of the territory of Poland showed a mean prevalence of $2.8 \%$. The highest prevalence of $E$. multilocularis was recorded in the north, the north-east and the south-east of Poland, $7.3 \%$, $18.8 \%$ and $7.2 \%$, respectively (Malczewski et al., 1999; Rocki et al., 1999; Machnicka et al., 2002). Later, within the EchinoRisk project (2001 - 2004) among 1514 foxes examined a high prevalence of $E$. multilocularis was found in the north-east (Warmia and Mazuria) and the south-east of Poland (Carpathian Foothill province) with $39.6 \%$ and $36.8 \%$ infected, respectively (EchinoRisk, 2005). It seems that a growing prevalence of E. multilocularis in foxes is noticeable in the whole territory of Poland. In 1996- 1997 Rocki et al. (1999) detected $0.6 \%$ infected among 79 examined in central Poland (Mazowieckie voivodship), however the studies in 2004 - 2006 demonstrated a mean prevalence of $13.5 \%$ among 379 foxes shot in this area, with the highest prevalence in the three districts, $21.1 \%$ $26.7 \%$ (Borecka et al., 2007). Furthermore, the racoon dog (Nyctereutes procyonoides) in the north of Poland was confirmed to be the final host of the tapeworm (Machnicka 
et al., 2002). Until now, among the 78 racoon dogs examined from the Pomerania region, four $(5.1 \%)$ were found infected (Gawor \& Malczewski, 2005).

The red foxes are known to be the most important predators in farmland areas. Their location may be related to the distribution of food resources or the presence of adequate habitats. On the other hand, both habitat and trophic condition regulate population dynamics. Several factors are regarded to be responsible for the high number of foxes, for example the intensive oral vaccination against rabies, a reduction in the intensity fox hunting and fox adaptation to new antropogenic conditions (Gołdyn et al., 2003).

An increase in the prevalence of E. multilocularis in Poland is most likely to be a result of the raise of the fox population (from 67000 in 1995 to over 200000 in 2006). An expansion of this canid species is probably, as in other European countries related to the antirabies campaigns. The actions started in 1993 in the western part of Poland and from 2002 were extended onto the whole territory. The dissimilarity in the prevalence of $E$. multilocularis in various regions is considered to be due to differences in geomorphological and ecological factors, which are crucial for the survival of tapeworm eggs and the biology of the definitive as well as the intermediate host of the parasite (Dubinsky et al., 2006). The diet of red fox was investigated by the analysis of 163 scats collected during 1998 2001 in western Poland (Wielkopolskie voivodship). In all cases, foxes fed predominantly on rodents and game birds, using poultry and garbage as an alternative food. The high frequency of rodent remains in scats $(89.6 \%)$ was related to the fact that foxes forage mainly in open habitats, where this prey is the most abundant. Among the rodents Microtus spp. predominated (67.5\%), especially $M$. arvalis (Gołdyn et al., 2003). This species is very common in wooded areas in Poland with its population density calculated as number of animal trapped/trap hours x $10^{4}$ being 17.1 and 6.24 in July 2006 and 2007, respectively (Paziewska unpublished). Pucek et al., (2003) examined two rodent species (A. flavicollis, C. glareolus) in northeastern Poland. The population of these species was influenced by four groups of factors, i.e. weather (June July temperatures, persistence of snow cover), food resources (seed crops), predation and social mechanism. Miterpakova et al. (2006) described significant correlation between prevalence of the tapeworms in red foxes and population density of small mammals.

Foxes examined in our study originated from uplandmountainous and woody regions, which favours the expansion of populations of the intermediate and the definitive host. Małopolskie province is situated west to the Carpathian Foothill voivodship, which southern part is regarded to be endemic for E. multilocularis, with prevalence exceeding $50 \%$ (EchinoRisk, 2005). In 2001 - 2004 in the Polish-Slovak borderland $41.6 \%-63.5 \%$ infected foxes were detected (Dubinsky et al., 2006). In this study, the host gender had no effect on the tapeworm prevalence, as $23 \%$ of females and $18.1 \%$ of males were found infected (not significant statistically). Dubinsky et al. (2006) found that in the Slovakia borderland the infection rate in both sexes was approximately at the same level $(28.0 \%$ of males and $30.3 \%$ of females), while at the Polish border area the prevalence was higher in male $(62.5 \%)$ than in female foxes $(42.3 \%)$. Because all foxes in the present study were older than one year, it was not possible to assess the influence of age on the level of infection. Other authors proved that the prevalence of E. multilocularis infection was higher in juvenile than in adult foxes (Losson et al., 2003). The number of specimens found in the present study was low, as $86 \%$ of the hosts examined possessed 1 100 worms and only $4.7 \%$ were highly infected ( $>1000)$. The method used (IST) makes it possible to estimate the intensity of infection only roughly, as only a part of the intestinal contents was inspected.

Climatic conditions in mountainous Carpathian region contribute to the survival of the parasite eggs. The high prevalence of E. multilocularis in foxes in some districts of Małopolskie voivodship is due to low annual temperatures and high annual rainfall in hilly areas which promote the dissemination of this zoonosis. The probable transborder transmission of E. multilocularis constitutes the enlargement risk of alveolar echinococcosis in the adjacent regions of Poland and Slovakia. The increased number of infected foxes is undoubtedly a reason of a growing number of alveolar echinococcosis (AE) cases in humans. Until now, fifty two AE cases have been reported in Poland (Chief Sanitary Inspectorate, 2007). The case recognised in Nowy Targ district in 2005 (22 year old woman) where a high prevalence of E. multilocularis in foxes was found in this study $(63.9 \%)$ confirms the high risk of infection in highly endemic areas. The total number of verified AE cases reported in 1982 - 2000 to the European Echinococcosis Registry was 559, with $42.0 \%$ diagnosed in France, $23.6 \%$ in Germany, and $21.1 \%$ in Switzerland (Kern et al., 2003). A majority of human AE cases were noted in the areas roughly corresponding to the regions of E. multilocularis incidents in the fox population. In these researchers' opinion, the place of residence of patients is most likely in accordance with the high endemicity in adjacent areas. Based on epidemiological data the risk factors for human alveolar echinococcosis were determineed to be dog or cat ownership, hunting, farming, gardening and eating food contaminated with Echinococcus eggs (Eckert et al., 2001). These activities may be characteristic for the most people in rural communities in Europe.

\section{Acknowledgements}

Financial support for this work was provided by the Ministry of Sciences and Higher Education in Poland (contract no. 2 PO5D 10729 "Investigations on infection of red foxes (Vulpes vulpes) with the tapeworm Echinococcus multilocularis in central and southern Poland"). 


\section{References}

BoreckA, A., GAWOR, J., MALCZEWSKA, M., MALCZEWSKI, A. (2007): Prevalence of tapeworm Echinococcus multilocularis in red foxes in central Poland. Med. Weter., 63: 1333 - 1335

Concise Statistical Yearbook of Poland. Central Statistical Office, Warsaw, 2007

DePlazes, P., ECKERT, J. (1996): Diagnosis of Echinococcus multilocularis infection in final hosts. Appl. Parasitol., 37: $245-252$

DEPLAZES, P., ECKERT, J. (2001): Veterinary aspect of alveolar echinococcosis- a zoonosis of public health significance. Vet. Parasitol., 98: $65-87$

Dubinsky, P., Malczewski, A., Miterpakova, M., GAWOR, J., REITEROVA, K. (2006): Echinococcus multilocularis in the red fox Vulpes vulpes from the East Carpathian region of Poland and the Slovak Republic. $J$. Helminthol., 80: 243 - 247

Eckert, J., Gemmelli, M. A., Meslin, F. X., PAwlowski, Z. S. (2001): WHO/OIE Manual on echinococcosis in humans and animals: A public health problem of global concern. World Organisation for Animal Health, France.

ECHINORISK (2005): Final report of the EU (FP5) project "Risk assessment and prevention of alveolar echinococcosis (EchinoRisk)", QLK2-CT-2001-01995.

GAWOR, J., MALCZEWSKI, A. (2005): The tapeworm in foxes as a cause of a dangerous zoonosis alveococcosis in Poland. (In Polish). Kosmos, 54: 89 - 94

GIESSEN VAN DER, J. W. B., ROMBOU, Y. B., FrANCHIMONT, J. H., LiMPER, L. P., HOMAN, W. L. (1999): Detection of Echinococcus multilocularis in foxes in The Netherlands. Vet. Parasitol., 82: 49 - 57

Goldyn, B., Hromada, M., Surmacki, A., TryjanowSKI, P. (2003): Habitat use and diet of the red fox Vulpes vulpes in an agricultural landscape in Poland. Z. Jagdwiss., 49: $191-200$

GOSZCZYŃSKI, J. (1985): The effect of structural differentiation of ecological landscape on the predator-prey interactions. Scientific trials and Monography of Warsaw University of Life Sciences, Warsaw, $1-80$

Kern, P., Bardonnet, K., Renner, E., Auer, H., PAWlowski, Z., AMmANn, R. W., VuitTon, D. A. (2003): European echinococcosis registry: human alveolar echinococcosis, Europe, 1982 - 2000. Res. Emerg. Infect. Dis., 9: 343 - 349

Losson, B., Kervyn, T., Detry, J., Pastoret, P. P.,
Mignon, B., BrochiER, B. (2003): Prevalence of Echinococcus multilocularis in red fox (Vulpes vulpes) in southern Belgium. Vet. Parasitol., 117: 23 - 28

Machnicka, B., Rocki, B., DzIEMian, E., KolodziejSoBOcIŃSKA, M. (2002): Racoon dog (Nyctereutes procyonoides) - the new host of Echinococcus multilocularis in Poland. Wiad. Parazytol., 48: 65 - 68

Malczewski, A., Rocki, B., RAmisz, A., EcKert, J. (1995): The causative agent of alveolar echinococcosis in humans: first record in Poland. J. Parasitol., 81: 318 - 321 Malczewski, A., RAmisz, A., Rocki, B., Bieńko, R., BALICKA-RAMISZ, A., ECKERT, J. (1999): Echinococcus multilocularis in red foxes (Vulpes vulpes) in Poland: an update of the epidemiological situation. Acta Parasitol., 44: $68-72$

Miterpakova, M., Dubinsky, P., Reiterova, K., STANKO, M. (2006). Climate and environmental factors influencing Echinococcus multilocularis occurrence in the Slovak Republic. Ann. Agric. Environ. Med., 13: 235 - 242 PUCEK, Z., JĘDRZEJEWSKI, W., JĘDRZEJEWSKA, B., PUCEK, M. (1993). Rodent population dynamics in a primeval deciduous forest (Białowieża National Park) in relation to weather, seed crop, and predation. Acta Theriol., 38: $199-232$

Reiterova, K., Dziemian, E., Miterpakova, M., Antolova, D., KoŁodzIEJ-SobocińsKA, M., MACHNICKA, B., DUBINSKY, P. (2006): Occurrence of Echinococcus multilocularis in red foxes from the Carpathian regions of Slovakia and Poland. Acta Parasitol., 51: 107 - 110

ROCKI, B., MALCZEWSKI, A., ECKERT, J. (1999): Studies on the incidence of Echinococcus multilocularis in red foxes (Vulpes vulpes) in north-east, central and south of Poland. Wiad. Parazytol., 45: 391 - 393

RoCKI, B. (2000): Helminths of intestinal tract of red foxes with special attention to Echinococcus multilocularis. $\mathrm{PhD}$ dissertation in Polish. Library W. Stefański Institute of parasitology of the Polish Academy of Sciences.

Romig, T., Dinkel, A., MACKenstedt, U. (2006): The present situation of echinococcosis in Europe. Parasitol. Int., 55: $187-191$

Veit, P., Bilger, B., Schad, V., Schäfer, J., Frank, W., LUCIUS, R. (1995): Influence of environmental factors on the infectivity of Echinococcus multilocularis eggs. Parasitology, 110: $79-86$

VoGEL, H. (1957): Über den Echinococcus multilocularis. Süddeutschlands Z. Tropenmed. Parasitol., 8: $404-454$ 